\title{
CONTROLE BIÓLOGICO DE NEMATOIDES UTILIZANDO MINHOCAS
}

\author{
Claudio Marques Tavares da Silva, Rita de Cássia Lima Mazzuchelli \\ ${ }^{1}$ Universidade do Oeste Paulista - UNOESTE, Curso de Agronomia, Presidente Prudente, SP, Brasil. E-mail: \\ claudiomarques_cj@hotmail.com
}

\section{RESUMO}

A pesquisa tem como objetivo avaliar a eficiência do uso de Lumbricus rubellus no controle de Meloidogyne incognita em raízes de Lactuca sativa. O experimento foi realizado no Laboratório de Microbiologia do Solo da Universidade do Oeste Paulista. Foi avaliada uma espécie de minhoca Lumbricus rubellus - em conjunto com nematoides da espécie Meloidogyne incognita, com adubação de estercos orgânicos - bovino e de aves. A cultura utilizada como teste foi a Lactuca sativa, e o estudo foi conduzido em solos de cultivo de hortaliças em vasos de 3 litros dentro de estufa com monitoramento de temperatura e umidade relativa do ar. Após 45 dias, os vasos foram retirados para análise, na qual observou-se que, quando comparada às outras situações analisadas, a integração de esterco de aves com as minhocas resultou em uma menor contagem de nematoides nas raízes e um melhor desenvolvimento da planta. Portanto, há uma possível chance de as minhocas serem eficientes para o controle biológico dos nematoides.

Palavras-chave: Meloidogyne, Minhocas, hortaliça, alface, Lumbricus rubellus

\section{BIOLOGICAL CONTROL OF NEMATODES USING EARTHWORM}

\begin{abstract}
The objective of this study was to evaluate the efficacy of using Lumbricus rubellus to control Meloidogyne incognita in Lactuca sativa roots. The experiment was carried out at the Laboratory of Soil Microbiology from the university Universidade do Oeste Paulista. We evaluated the worm species Lumbricus rubellus together with nematodes of the species Meloidogyne incognita and used fertilization with organic manure (cow and bird). For testing, we used Lactuca sativa, and the study was done using soil for growing vegetables in three-litter pots inside a greenhouse where relative humidity and temperature were monitored. After 45 days, the pots were removed and analysed. Analysis showed that, in comparison to the other situations analysed, the combination of bird manure with the worms resulted in a lower count of nematodes in the roots and better development of the plants. Therefore, there is a possibility these worms are effective in the biological control of nematodes.
\end{abstract}

Key words: Meloidogyne, Earthworm, Vegetable, Lettuce, Lumbricus rubellus

\section{INTRODUÇÃO}

A alface (Lactuca sativa L.) da família Asteraceae (Compositae) originou-se de espécies silvestres e, atualmente, é encontrada nas regiões de clima temperado - no sul da Europa e na Ásia Ocidental. É uma espécie herbácea que possui folhas finas e delicadas que se organizam em rosetas ao redor de um caule diminuto e não ramificado (FILGUEIRA, 2008).

$\mathrm{O}$ aumento da produção de hortaliças deve-se à crescente expansão populacional e, também, à tendência na mudança do hábito alimentar pelo consumidor. Como o consumidor 
torna-se cada vez mais exigente, há a necessidade de produzir grande quantidade e boa qualidade de hortaliças durante o ano todo (OHSE et al., 2001).

De maneira geral, as hortaliças são altamente exigentes com relação a fertilizantes nitrogenados prontamente solúveis. A obtenção de sua alta produtividade depende da aplicação de elevadas doses de fertilizantes minerais, os quais são derivados de processos industriais de intenso uso energético, pois os solos de regiões tropicais são, originalmente, pobres em matéria orgânica (COELHO et al., 2011).

Entre os vegetais, a alface (Lactuca sativa) é uma cultura demasiadamente suscetível à infestação por nematoides das galhas, especialmente Meloidogyne incognita e Meloidogyne javanica (Sikora \& Fernandez, 2005).

Esses patógenos têm alta taxa de reprodução, o que resulta no acúmulo de grandes quantidades de ovos no solo (Campos et al., 2001).

A grande dificuldade na investigação de fitonematoides em lavouras está ligada à natureza dinâmica desses organismos no solo. O sistema ecológico em que vivem os fitonematoides, é uma complexa interação entre a planta hospedeira, o microclima, as propriedades físicas e químicas do solo e os microrganismos (Laughlin \& Lordello, 1977).

As estratégias de manejo para se diminuir a população de nematóides são: cultural, biológico, químico e genético (GONÇALVES et al., 1998), sendo o último o mais eficaz e viável economicamente. Entretanto, conforme GONÇALVES et al. (1998), a principal estratégia de manejo é, ainda, evitar a disseminação de fitonematóides por solos, águas e culturas.

Minhocas interagem de forma generalizada com os processos físicos (hidrológico e gasoso) que ocorrem no perfil do solo e, dessa forma, contribuem para o aumento da porosidade, aeração e infiltração de água (BLANCHART et al., 1999). Em relação aos aspectos biológicos, elas estão intimamente relacionadas com a comunidade microbiana, a microfauna e as plantas, assim como envolvidas na decomposição e mineralização da matéria orgânica do solo (BONKOWSKI et al., 2000).

O objetivo do presente trabalho foi avaliar a eficácia da Lumbricus rubellus com estercos orgânicos na redução de galhas de $M$. incognita das raízes de Lactuca sativa.

\section{METODOLOGIA}

O experimento foi conduzido no Laboratório de Biologia do solo da Universidade do Oeste Paulista (UNOESTE), dentro da estufa de vegetação Fitotron, com delineamento experimental inteiramente casualizado, com seis tratamentos e quatro repetições (24 unidades experimentais): T1. Controle; T2. Adição ao solo de Lumbricus rubellus; T3. Inoculação ao solo de Meloidogyne incognita; T4. Adição ao solo de Lumbricus rubellus e inoculação de Meloidogyne incognita; T5. Adição ao solo de Lumbricus rubellus, inoculação de Meloidogyne incognita e adição de esterco bovino; T6. Adição ao solo de Lumbricus rubellus, inoculação de Meloidogyne incognita e adição de esterco de aves.

As unidades experimentais foram montadas em vasos de plástico com capacidade para 3L, e o solo utilizado foi o de cultivo de hortaliças.

Previamente, foram selecionadas seis minhocas adultas caracterizadas com a presença do clitelo de Lumbricus rubellus. Elas foram inoculadas aos vasos isoladamente. (T2, T4, T5, T6).

Após uma semana de ambientalização das minhocas, foram transplantadas mudas de Lactuca sativa e, no mesmo dia, feita a inoculação dos nematoides com dose de $30 \mathrm{~mL} /$ planta contendo 5000 ovos/juvenis em superfície.

A pesquisa foi mantida com regas diárias e monitoramento de temperatura e umidade relativa do ar.

Após um período de 45 dias, as plantas foram retiradas para a seguinte análise: número de folhas por planta, considerando-se todas as folhas que apresentam tamanho mínimo ou superior a 
$1,0 \mathrm{~cm}$; massa fresca da parte aérea, aferido após o corte rente ao solo, foram destinadas à balança analítica de precisão para saber seu peso em matéria seca e verificado o teor de clorofila com auxílio do clorofilômetro -, utilizando-se a maior folha da planta como parâmetro; contagem das minhocas remanescentes e análises nematologias seguindo metodologia de Jenkins (1964).

Os dados obtidos serão submetidos à análise de variância através do programa Sisvar (FERREIRA, 2008). E teste de Tukey a 1 e $5 \%$ de probabilidade para a comparação das médias dos tratamentos.

\section{RESULTADOS}

A avaliação das plantas de Lactuca sativa teve como resultado: em número de folhas não houve variações significativas, entretanto, na análise de sua matéria seca o esterco bovino demonstrou uma variação significativa comparada ao controle e à inoculação dos nematoides. Na análise de teor de clorofila, o esterco de aves demonstrou diferença se comparado ao controle e à inoculação dos nematoides, verificados na tabela 1.

Tabela 1. Número de folhas - NF, Massa fresca parte aérea - MFPA, Clorofila

\begin{tabular}{llll}
\hline Tratamentos & NF & MFPA & Clorofila \\
\hline Controle & $15,0 \mathrm{a}$ & $77,2 \mathrm{c}$ & $20,2 \mathrm{ab}$ \\
T2. L. rubellus & $17,5 \mathrm{a}$ & $86,9 \mathrm{abc}$ & $27,3 \mathrm{a}$ \\
T3. M. incognita & $15,5 \mathrm{a}$ & $64,6 \mathrm{c}$ & $17,6 \mathrm{~b}$ \\
T4. L. rubellus + M. incognita & $17,7 \mathrm{a}$ & $82,9 \mathrm{bc}$ & $21,8 \mathrm{ab}$ \\
T5. L. rubellus + M. incognita + EB & $16,0 \mathrm{a}$ & $129,25 \mathrm{a}$ & $26,4 \mathrm{a}$ \\
T6. L. rubellus +M. incognita + AV & $18,2 \mathrm{a}$ & $122,7 \mathrm{ab}$ & $27,3 \mathrm{a}$ \\
\hline F & $0,41^{\text {ns }}$ & $7,30^{* *}$ & $5,36^{* *}$ \\
\hline C.V. (\%) & 24,94 & 20,50 & 15,26 \\
\hline
\end{tabular}

Letras iguais nas colunas não diferem significativamente pelo teste de Tukey a $5 \%$ de probabilidade.

Quanto à avaliação da permanência de minhocas nos vasos, não houve variações significativas entre os tratamentos com inoculação das minhocas; já na contagem de nematoides houve diferenças no tratamento com adubação de esterco de aves em conjunto com as minhocas, quando comparado ao controle e àquele com apenas a inoculação dos nematoides, verificados na tabela 2.

Tabela 2. PERMANÊNCIA DAS MINHOCAS - PERMAN, NEMATOIDES - NEMATO

\begin{tabular}{lll}
\hline Tratamentos & PERMAN & NEMATO \\
\hline Controle & $0,0 \mathrm{~b}$ & $19,7 \mathrm{ab}$ \\
T2. L. rubellus & $95,8 \mathrm{a}$ & $17,5 \mathrm{~b}$ \\
T3. M. incognita & $0,0 \mathrm{~b}$ & $23,7 \mathrm{a}$ \\
T4. L. rubellus + M. incognita & $79,1 \mathrm{a}$ & $16,5 \mathrm{~b}$ \\
T5. L. rubellus + M. incognita + EB & $95,8 \mathrm{a}$ & $19,2 \mathrm{ab}$ \\
T6. L. rubellus +M. incognita + AV & $100,0 \mathrm{a}$ & $16,5 \mathrm{~b}$ \\
\hline F & $67,8^{\text {ns }}$ & $5,23^{* *}$ \\
\hline C.V. (\%) & 19,02 & 12,74 \\
\hline
\end{tabular}

Letras iguais nas colunas não diferem significativamente pelo teste de Tukey a $5 \%$ de probabilidade.

\section{DISCUSSÃO}

Os procedimentos de controle de nematoides implicam reduzir as populações de tal modo que ocorra menos infecção nas raízes, do que poderia ocorrer sem as medidas adotadas (TAYLOR; 
SASSER, 1978). Nematicidas químicos são caros e poluentes, por isso, métodos alternativos de controle são de grande importância para a produção agrícola sustentável (NEVES et al., 2009).

A inoculação das minhocas Amynthas spp. e Pontoscolex corethrurus, individualmente ou associadas, foi capaz de reduzir o número de galhas/ planta, demonstrando a importância dessa técnica de controle biológico do M. paranaensis. Dominguez, Parmelee e Edwards (2003) constataram a redução do número de nematoides após a passagem pelo trato digestivo das minhocas.

A inoculação de plantas de banana (Musa acuminata) com o Rhadopholus similis (Cobb) Thorne e Pontoscolex corethrurus Muller, 1857, demonstrou que, apesar de as minhocas não terem reduzido significativamente o número de nematoides, o crescimento vegetal e a nutrição mineral das plantas foram influenciados positivamente pela ação delas (LAFONT et al., 2007).

O uso de adubação orgânica estimula a comunidade de minhocas, o que pode contribuir para a sustentabilidade do sistema do solo. Ao estimular as populações de minhocas, em futuras pesquisas, deve-se quantificar a quantidade de irrigação preferencial para elas, realizar as contagens de novas minhocas que venham a nascer, medir o tamanho das raízes e contar suas galhas e fazer testes em solos de lavoura.

A avaliação da população de nematoides dos gêneros Meloidogyne mostrou que os tratamentos diferiram em relação ao controle e ao tratamento com o nematoide apenas; com a inoculação das minhocas, houve diminuição na contagem de nematoides nas raízes, o que beneficiou o crescimento das plantas. A adubação com esterco de aves demonstrou um melhor resultado devido, talvez, ao seu maior teor de Nitrogênio. Portanto, a consorciação no sistema de minhocas com esterco de aves é um possível método efetivo de controle de nematoides do gênero Meloidogyne.

\section{CONCLUSÃO}

A utilização de minhocas no controle de nematoides se mostrou eficiente, controlando em $30 \%$ a infestação de nematoides. O tratamento com o uso de minhocas e esterco bovino no controle de nematoides possibilitou o dobro da produção da alface em relação à adição de nematoides.

\section{REFERÊNCIAS}

ALVES, F.R.; CAMPOS, V.P. Efeito do aquecimento do solo na resistência de plantas a Meloidogyne javanica e Meloidogyne incognita raça 3. Nematologia Brasileira, Brasília, v.25, n.2., p.153- 162,

Dez. 2001.

BLANCHART, E.; ALBRECHT A.; ALEGRE, J.; DUBOISSET, A.; GILOT, C.; PASHANASI, B.; LAVELLE, P.; BRUSSSAARD, L. Effects of earthworms on soil structure and physical properties. In: LAVELLE, P.; BRUSSAARD, L.; HENDRIX. P. (Ed.). Earthworms management in tropical agroecosystems.CAB International: Wallingford, 1999. p. 149-172

BONKOWSKI, M., B.S. GRIFFITHS, and K. RITZ. 2000. Food preferences of earthworms for soil fungi, Pedobiologia, 44, 666-676. https://doi.org/10.1078/S0031-4056(04)70080-3

COELHO, Alexsandro Alves et al. 10880 - Efeitos da adubação verde, na forma de pré-cultivo, na produção de diferentes cultivares de alface sob manejo agroecológico. Cadernos de Agroecologia, [S.I.], v. 6, n. 2, nov. 2011. ISSN 2236-7934.

FILGUEIRA. Novo manual de olericultura: agrotecnologia moderna na produção e comercialização de hortaliças. Viçosa: UFV. 2008. 421p. 
GONÇALVES, W.; SILVAROLLA, M. B.; LIMA, M. M. A. de. Estratégias visando a implementação do manejo integrado dos nematóides parasitos do cafeeiro. Informe Agropecuário, Belo Horizonte, v. 19, n. 193, p. 36-47, 1998.

LAUGHLIN, C. W.; LORDELLO, L. G. E. Sistemas de manejo de nematoides: relações entre a densidade de população e os danos à planta. Nematologia Brasileira, Piracicaba, v.2, p.15-24, 1977.

LAFONT, A.; RISEDE, J. M.; LORANGER-MERCIRIS, G.; DAUPHIN, C. C.; DOREL, M.; RHINO, B.; LAVELLE, P. Effects $0 \pm$ the earthworm Pontoscolex corethruruson banana plants infected or not with the plant-parasitic nematode Radopholus similis. Pedobiologia, Jena, v. 51, n. 4, p. 311-318, 2007. https://doi.org/10.1016/i.pedobi.2007.05.004

NEVES, W. S.; FREITAS, L. G.; COSTA, M. D.; ALMEIDA, V. S.; FERRAZ, S. Controle de Meloidogyne javanica pelo uso de bactérias isoladas de solo biofumigado com resíduos de diferentes espécies de brássicas. Nematologia Brasileira, Campinas, v. 33, n. 2, p. 132-138, 2009.

OHSE, S.; DOURADO-NETO, D.; MANFRON, P. A.; SANTOS, O. S. Qualidade de cultivares de alface produzidos em hidroponia. Scientia Agricola, Piracicaba, v. 58, n. 1, p. 181-185, 2001. https://doi.org/10.1590/S0103-90162001000100027

SIKORA A; FERNÁNDEZ E. 2005. Nematode parasites of vegetables. In: LUC M; SIKORA RA; BRIDGE J. (eds). Plant Parasitic Nematodes in Subtropical and Tropical Agriculture. Wallingford, UK: CAB International, p.319-392. 